\title{
T-CELL RECONSTITUTION AFTER UNMANIPULATED, CD8- DEPLETED OR CD34-SELECTED NONMYELOABLATIVE PERIPHERAL BLOOD STEM-CELL TRANSPLANTATION
}

\author{
Frédéric Baron, ${ }^{1,2}$ Nicole SchaAf-Lafontaine, ${ }^{3}$ STÉphanie Humblet-Baron, ${ }^{1}$ \\ Nathalie Meuris, ${ }^{1,2}$ Emilie Castermans, ${ }^{1,2}$ Etienne Baudoux,${ }^{1,2}$ Pascale Frère, ${ }^{1}$ \\ Vincent Bours, ${ }^{2,4}$ Georges Fillet, ${ }^{1,2}$ ANd Yves Beguin ${ }^{1,2,5}$
}

\begin{abstract}
Background. We have previously shown that CD8 depletion or CD34 selection of peripheral blood stem cells (PBSC) reduced the incidence of acute graft-versus-host disease (GvHD) after nonmyeloablative stemcell transplantation (NMSCT). In this study, we analyze the effect of CD8 depletion or CD34 selection of the graft on early T-cell reconstitution.
\end{abstract}

Methods. Nonmyeloablative conditioning regimen consisted in 2 Gy total-body irradiation (TBI) alone, 2 Gy TBI and fludarabine, or cyclophosphamide and fludarabine. Patients 1 to 18 received unmanipulated PBSC, patients 19 to 29 CD8-depleted PBSC, and patients 30 to 35 CD34-selected PBSC.

Results. T-cell counts, and particularly $\mathrm{CD}^{+}$and CD4CD45RA $^{+}$counts, remained low the first 6 months after nonmyeloablative stem-cell transplantation $($ NMSCT) in all patients. CD34 selection $(P<0.0001)$ but not CD8 depletion of PBSC significantly decreased Tcell chimerism. Donor T-cell count was similar in unmanipulated compared with CD8-depleted PBSC recipients but was significantly lower in CD34-selected PBSC recipients $(P=0.0012)$. $T$ cells of recipient origin remained stable over time in unmanipulated and CD8depleted PBSC patients but expanded in some CD34selected PBSC recipients between day 28 and 100 after transplant. Moreover, whereas CD8 depletion only decreased $\mathrm{CDB}^{+}$counts $(P<0.047), \mathrm{CD34}$ selection reduced $\mathrm{CD3}^{+}(\boldsymbol{P}<0.001), \mathrm{CD8}^{+}(P<0.016), \mathrm{CD4}^{+}(P<0.001)$, and $\mathrm{CD4}^{+} \mathrm{CD}^{-} \mathrm{RAA}^{+}(P<0.001)$ cell counts. T-cell repertoire was restricted in all patients on day 100 after hematopoietic stem-cell transplantation but was even more limited after CD34 selection $(P=0.002)$.

Conclusions. Despite of the persistence of a significant number of $T$ cells of recipient origin, $T$-cell counts were low the first 6 months after NMSCT. Moreover, contrary with CD8 depletion of the graft that only affects $\mathrm{CD8}^{+}$lymphocyte counts, CD34 selection dramatically decreased both CD8 and CD4 counts.

This work was supported by grants from "La Fondation BonjeanOleffe," "L'Association sportive contre le Cancer," "Le Fonds de Recherche Scientifique du CHU Sart-Tilman," and the National Fund for Scientific Research (FNRS, Belgium).

${ }^{1}$ Department of Medicine, Division of Hematology, University of Liège, Liège, Belgium.

${ }^{2}$ Center for Cellular and Molecular Therapy, Department of Clinical Biology, University of Liège, Liège, Belgium.

${ }^{3}$ Division of Laboratory Hematology, University of Liège, Liège, Belgium.

${ }^{4}$ Department of Genetics, University of Liège, Liège, Belgium.

${ }^{5}$ Address correspondence to: Dr. Yves Beguin, University of Liège, Department of Hematology, CHU Sart-Tilman, 4000 Liège, Belgium. E-mail: yves.beguin@chu.ulg.ac.be.

Received 13 May 2003. Accepted 27 June 2003.

DOI: 10.1097/01.TP.0000093987.11389.F7
Allogeneic hematopoietic stem-cell transplantation (alloHSCT) remains the only curative treatment for several hematologic malignancies (1). However, because of its toxicity, this approach is restricted to younger and fitter patients. Since the late 1970 s, donor alloreactivity against tumor cells has been recognized as a major factor in the success of alloHSCT (1). This graft-versus-leukemia (GvL) effect is so potent that some leukemia relapses after standard allogeneic transplantation can be effectively treated (70\% long-term complete remission in chronic myeloid leukemia) with donor lymphocyte infusions (DLI) $(2,3)$. This observation led several groups to set up new (less-toxic) transplant protocols (NMSCT) based on a two-step approach: first, the use of immunosuppressive (but nonmyeloablative) preparative regimens providing sufficient immunosuppression to achieve engraftment of allogeneic HSC and, in a second step, the destruction of malignant cells by the GvL effect (4). On the basis of extensive animal studies (5), the Seattle team has proposed an original approach to NMSCT with a conditioning regimen based on single-dose (2 Gy) total-body irradiation (TBI) \pm fludarabine $\left(90 \mathrm{mg} / \mathrm{m}^{2}\right)$, followed by posttransplant immunosuppression with cyclosporine A (CsA) and mycophenolate mofetil (MMF) that permitted the performance of the transplant in an ambulatory care setting (5-7). The authors observed a low transplant-related mortality (even in older patients), which was most often attributed to graft-versushost disease $(\mathrm{GvHD})$ or infections $(6,7)$. Thus, one major objective to improve outcome following NMSCT is to achieve rapid T-cell reconstitution (to permit the occurrence of the GvL effect (8) and avoid opportunistic infections), without severe GvHD.

T-cell depletion (TCD) of the graft has been associated with a decreased incidence of GvHD (9). However, TCD can also contribute to increased rates of graft failure as well as to significant delays in immune reconstitution, leading to high incidences of infection and leukemia relapse (9).

Several observations suggest that CD8 depletion could decrease the incidence of GvHD without compromising the GvL effect after a standard allo-HSCT, at least for CML and multiple myeloma patients $(10-12)$. However, the impact of CD8 depletion on immune recovery is not known. Similarly, although several reports suggest that a strategy of TCD of the graft followed by preemptive DLI may permit decrease in the incidence of GvHD without impairing the GvL effect (13-15), immune recovery after CD34-selected peripheral blood stem-cell (PBSC) transplantation followed by preemptive DLI is also largely unknown.

We previously showed that CD8 depletion or CD34 selection of PBSC apparently reduced the incidence of acute 1705 
GvHD after NMSCT $(16,17)$. In this report, we analyzed immune reconstitution after unmanipulated, CD8-depleted, or CD34-selected NMSCT.

\section{PATIENTS AND METHODS}

\section{Patients and Donors}

Fifty consecutive patients ineligible for a myeloablative allogeneic HSCT were initially included. Fifteen patients were excluded from the analysis of immune reconstitution because of early death $(n=10)$, early graft rejection $(n=2)$, inadequate follow-up $(n=2)$, or bone marrow instead of PBSC as stem-cell source $(n=1)$. Thus, 35 patients with malignancies and a human leukocyte antigen (HLA)-identical sibling $(n=17)$ or alternative donor $(n=18,6$ related 1-mismatch and 12 unrelated HLA-identical donors) were analyzed. Fifty-seven percent of them had received a prior autotransplant (proportion not significantly different among the groups). Their clinical characteristics are summarized in Table 1. Donors received recombinant human granulocyte colony-stimulating factor (G-CSF) (Neupogen, kindly provided by Amgen, Brussels, Belgium) at $10 \mu \mathrm{g} / \mathrm{kg}$ from day -5 through day -1 before transplant. Collection of PBSC was carried out on days -1 and 0 using a continuous-flow blood-cell separator (CS3000+, Baxter-Fenwall Laboratories, Deerfield, IL, or Cobe Spectra, Lakewood, CO) as previously reported $(14,16)$. The nonmyeloablative conditioning regimen consisted in 2 Gy TBI alone $(n=15)$, 2 Gy TBI and $90 \mathrm{mg} / \mathrm{m}^{2}$ fludarabine (previously untreated patients, $\mathrm{n}=13)$, or cyclophosphamide $\left(3 \mathrm{~g} / \mathrm{m}^{2}\right)$ and fludarabine $\left(90 \mathrm{mg} / \mathrm{m}^{2}\right)$ (patients who had previously received a full-dose TBI, $n=7$ ). In the context of a prospective comparative trial of NMSCT, patients 1 to 18 received unmanipulated PBSC, patients 19 to 29 CD8-depleted PBSC, and patients 30 to 35 CD34-selected PBSC. Posttransplant immunosuppression was carried out with CsA (from day -1 to day 120 or longer in case of alternative donor or chronic GvHD) and MMF
(15 mg/kg twice a day from day -1 to day 28 ) as previously described (18). At approximately day 40 posttransplantation, donors underwent 12 to $16 \mathrm{~L}$ leukaphereses on 2 consecutive days to collect lymphocytes. Patients 1 to 18 transplanted with unmanipulated PBSC were assigned to receive unmanipulated preemptive DLI $\left(1 \times 10^{7}\right.$ and $2 \times 10^{7} \mathrm{CD}^{+}$cells/kg at approximately days 40 and 80 , respectively), whereas patients 19 to 35 transplanted with CD8depleted or CD34-selected PBSC were assigned to receive CD8depleted DLI $\left(1 \times 10^{7}\right.$ and $5 \times 10^{7} \mathrm{CD}^{+}$cells/kg [2 in mismatched transplants] per recipient at approximately days 40 and 80 , respectively). The first DLI was infused fresh, whereas the following were cryopreserved and thawed. DLI were not to be given in case of an antecedent grade III to IV acute GvHD or active GvHD at time of scheduled infusions nor in recipients of unrelated transplants. Patients with mixed chimerism (MC) on day 100 received a third DLI at approximately day 120. CD34 selection and CD8 depletion of PBSC and DLI were carried out with Nexell Isolex 300i (Nexell International, Wemmel, Belgium) as previously reported $(14,16)$. Written informed consent was obtained from patients and donors, and our institution's ethical committee approved the protocol.

\section{Clinical Management}

The trigger values for red blood cell and platelet transfusion were 8.0 $\mathrm{g} / \mathrm{dL}$ and $15 \times 10^{9} / \mathrm{L}$, respectively. G-CSF ( $5 \mu \mathrm{g} / \mathrm{kg}$ per d) was administered only when the granulocyte count was below $1.0 \times 10^{9} / \mathrm{L}$. The diagnosis and grading of acute GvHD was established as previously reported $(18,19)$. Disease evaluation was routinely carried out on days 40 , 100, 180, and 365. Polymerase chain reaction (PCR) for cytomegalovirus (CMV) was performed weekly until day 100 and every 2 to 4 weeks thereafter. Patients with a positive PCR received preemptive ganciclovir for a minimum of 4 weeks and generally up to day 100 .

TABLE 1. Characteristics of patients

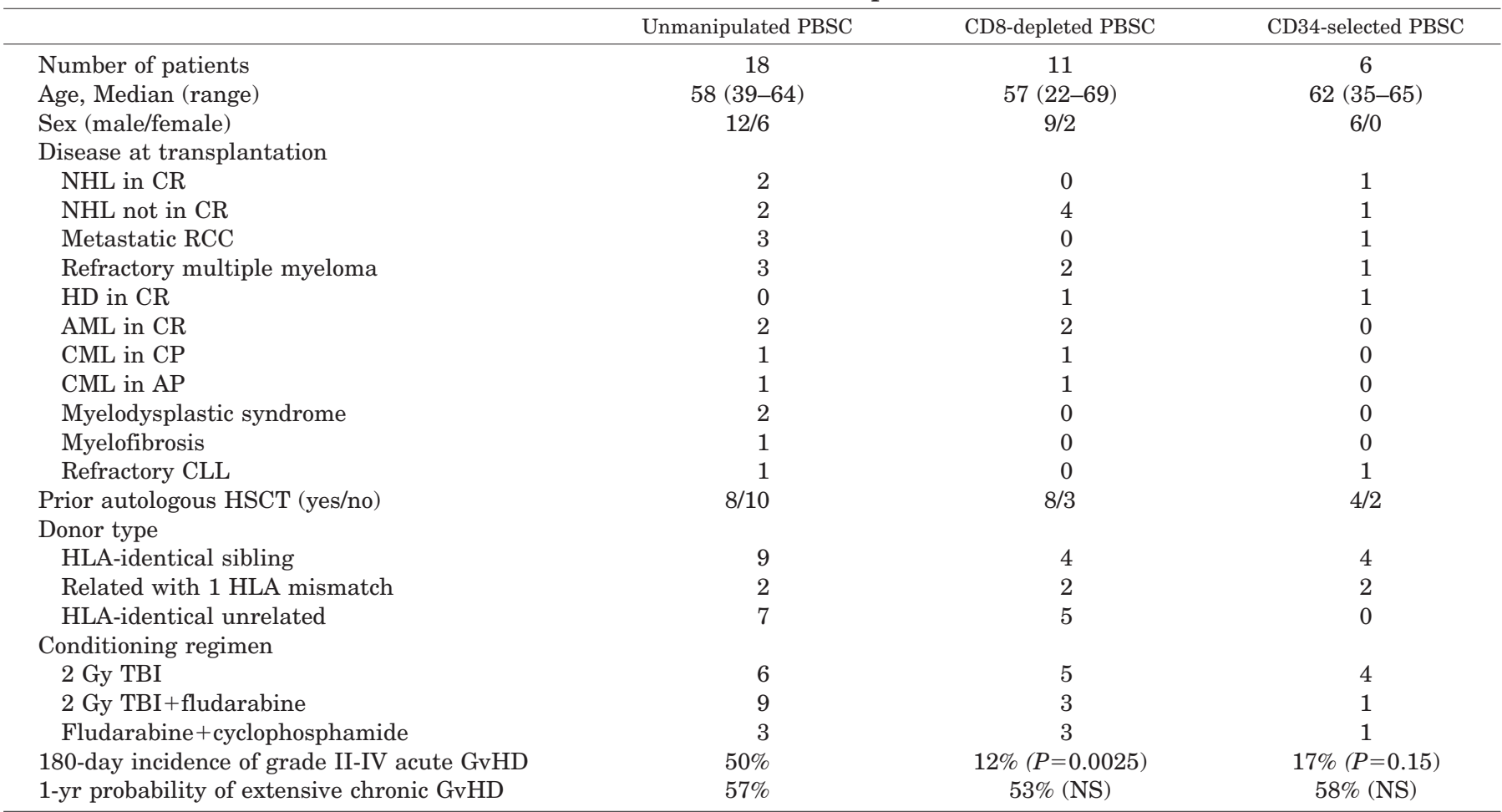

NHL, non-Hodgkin's lymphoma; CR, complete response; RCC, renal-cell carcinoma; HD, Hodgkin's disease; AML, acute myeloid leukemia; CML, chronic myeloid leukemia; CP, chronic phase; AP, accelerated phase; CLL, chronic lymphocytic leukemia; PBSC, peripheral blood stem cell; HSCT, hematopoietic stem-cell transplantation; HLA, human leukocyte antigen; TBI, total-body irradiation; GvHD, graft-versus-host disease. 


\section{Laboratory Analyses on PBSC and DLI}

Aliquots of the pooled PBSC as well as the CD8-depleted or CD34selected fractions were incubated with fluorescein isothiocyanate (FITC)- or phycoerythrin (PE)-conjugated anti-CD34, CD3, CD4, CD45RA, CD45RO, CD19, CD8, and CD56 monoclonal antibodies for 20 minutes at $20^{\circ} \mathrm{C}$ and were washed and fixed. A total of $1 \times 10^{5}$ cells per condition were analyzed using a FACS-scan analyzer (BectonDickinson, San Jose, CA). The percentage of positive cells was defined with dot-plot analysis using the whole nucleated cell population. The percentage of positive cells in the isotype control was subtracted from the positive-cell percentage to give the final percentage of positive cells. Data acquisition was performed with the Cellquest software (Becton-Dickinson). Donor lymphocytes (before and after CD8 depletion) were similarly examined using double labeling with FITC- and PE-conjugated antibodies after treatment with a lysing solution.

\section{Chimerism Analysis}

Chimerism among total peripheral blood white blood cells (WBC), $\mathrm{T}$ cells, and myeloid cells as well as in unfractionated marrow was assessed at days 28, 60, 100, and 180 after HSCT using fluorescence in situ hybridization to detect $\mathrm{X}$ and $\mathrm{Y}$ chromosomes for recipients of sex-mismatched transplants and PCR-based analysis of polymorphic microsatellite regions for recipients of sex-matched transplants (16). CD3 (T cells) and CD13/CD33 (myeloid cells) selection was carried out with a FACStar Plus sorter (Becton-Dickinson) or with RosetteSep (StemCell Technologies, Vancouver, Canada). MC was defined as between 5\% and 94\% donor cells and full chimerism as $95 \%$ or more of donor cells.

\section{Immune Recovery}

Patients' peripheral WBC were examined on days 28, 42, 60, 80, 100,120 , and 180 using double labeling with FITC- and PE-conjugated antibodies before treatment with a lysing solution. Cell subsets analyzed were T cells $\left(\mathrm{CD} 3^{+}\right), \mathrm{CD} 4^{+}$lymphocytes, $\mathrm{CD} 8^{+}$ lymphocytes, $\mathrm{CD} 4^{+} \mathrm{CD} 45 \mathrm{RA}^{\text {high }}$ double-positive lymphocytes, $\mathrm{CD}^{+}{ }^{+} \mathrm{CD} 45 \mathrm{RO}^{+}$double-positive lymphocytes, $\mathrm{CD}^{+} 6^{+}$cells, as well as $\mathrm{CD} 19^{+} \mathrm{B}$ lymphocytes. The percentage of positive cells was defined with dot-plot analysis using the whole nucleated cell population. The percentage of positive cells in the isotype control was subtracted from the positive-cell percentage to give the final percentage of positive cells. Each absolute cell subset count was then calculated by multiplying this percentage by the absolute nucleated cell count (determined by an Advia cell counter, Bayer, Milan, Italy). Data acquisition was performed with the Cellquest software (Becton-Dickinson). Lower and higher limits for each cell subset were defined, respectively, as the 3rd and 97th percentile of values obtained in 30 healthy blood donors.

\section{Natural-Killer Activity Assay}

PBMC were obtained by Ficoll (Nycomed Pharma SA, Oslo, Norway) on days $28,42,60,80,100,120,140,160$, and 180 and were tested for cytotoxicity against the natural killer (NK)-sensitive cell line K562 in a ${ }^{51} \mathrm{Cr}$-release assay as previously described (20). Target cells (K562) were labeled with $200 \mu \mathrm{Ci}{ }^{51} \mathrm{Cr}$ sodium chromate for 60 minutes, washed three times, and added at a concentration of $1 \times 10^{5}$ cells per well to round-bottomed microtiter plates. Effector cells (recipient PBMC) were added at effector:target ratios ranging from 50:1 to $1: 1$ in a final volume of $200 \mu \mathrm{L}$ per well. The plates were incubated for 4 hours at $37^{\circ} \mathrm{C}$ in a humidified atmosphere with $5 \%$ $\mathrm{CO}_{2}$. Maximum ${ }^{51} \mathrm{Cr}$ release was ensured by addition of detergent and spontaneous release by addition of complete medium to the target cells. The culture supernatant was harvested after centrifugation and counted in a gamma counter. All determinations were performed in triplicate, and the percentage of specific lysis was calculated as (Experimental cpm-Spontaneous cpm)/(Maximum cpm-Spontaneous $\mathrm{cpm}) \times 100$. The NK activity was corrected by dividing the percentage of specific lysis by the percentage of CD56 ${ }^{+}$ cells in the culture.

\section{CDR3 Spectratyping}

CDR3 spectratyping (immunoscope) was performed on day 100. RNA was extracted from 10 to $30 \times 10^{6}$ PBMC by Tripure (Roche, Indianapolis, IN) according to the manufacturer's protocol. Firststrand cDNA was generated from $2 \mu \mathrm{g}$ total RNA using 1st Strand cDNA Synthesis Kit for reverse transcriptase-PCR (Roche) according to the manufacturer's protocol. Each TCR V $\beta$ segment was amplified with one of the $24 \mathrm{~V} \beta$ subfamily specific primers $(\mathrm{V} \beta 1-\mathrm{V} \beta 24)$ and a $\mathrm{C} \beta$ primer conjugated to fluorescent dye 6-FAM (Applied Biosystems, Lennik, Belgium) for CDR3 analysis (21). The size distribution of each fluorescent PCR product was determined by electrophoresis on an automated DNA sequencer (Applied Biosystems, Foster City, $\mathrm{CA}$ ), and data were analyzed by GeneScan-500 software (Perkin Elmer Cetus Instruments, Emeryville, CA). The overall complexity within a $\mathrm{V} \beta$ subfamily was determined by counting the number of peaks (intervals of 3 nucleotides without any gaps) per subfamily. Normal complexity of subfamily was defined as consisting of at least six peaks spaced three nucleotides apart without any gaps. The overall spectratyping complexity ( $\mathrm{V} \beta$ score) was calculated as the sum of the number of peaks in the 24 subfamilies.

\section{Statistical Analyses}

T-cell subset recovery as well as evolution of T-cell chimerism in the CD8-depleted and CD34-selected groups were analyzed in comparison with the unmanipulated group by the two-way analysis of variance test using graft manipulation and time as variables. Recovery of $\mathrm{CD}^{+}$cells of donor or recipient origin was calculated by multiplying the $\mathrm{CD}^{+}$cell count by the percentage of donor or host T-cell chimerism, respectively. On the basis of the spectratype complexity of five normal donors, we established a score of 176 , based on the $95 \%$ lower confidence interval, as the lower limit of normal. Student's $t$ test was used to assess the difference in $\mathrm{V} \beta$ score between the normal donors and the patients. Spearman's rank correlation was used to examine the relationship between parameters. Statistical analyses were carried out with Graphpad Prism (Graphpad Software, San Diego, CA).

\section{RESULTS}

\section{Composition of the Graft}

Patients 1 to 18 received unmanipulated PBSC containing a median of $6.0(0.8-14.9) \times 10^{6} \mathrm{CD}^{+} 4^{+}$cells $/ \mathrm{kg}$ recipient, 321 $(80-522) \times 10^{6} \mathrm{CD}^{+}$cells $/ \mathrm{kg}, 196(38-394) \times 10^{6} \mathrm{CD}^{+}$cells/ $\mathrm{kg}, 118(43-178) \times 10^{6} \mathrm{CD}^{+}$cells $/ \mathrm{kg}$, and $63(5-395) \times 10^{6}$ $\mathrm{CD} 6^{+}$cells/kg, respectively. Patients 19 to 29 received CD8depleted PBSC containing a median of $5.4(1.6-8.4) \times 10^{6}$

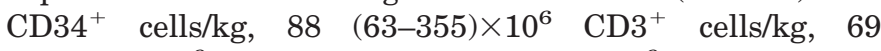
$(55-225) \times 10^{6} \mathrm{CD}^{+}$cells $/ \mathrm{kg}, 2(0.5-32) \times 10^{6} \mathrm{CD}^{+}$cells $/ \mathrm{kg}$, and $28(17-78) \times 10^{6} \mathrm{CD}^{+} 6^{+}$cells/kg, respectively. Patients 30 to 35 received CD34-selected PBSC containing a median of $5.5(1.8-8.8) \times 10^{6} \mathrm{CD}^{+} 4^{+}$cells $/ \mathrm{kg}, 0.07(0.04-0.11) \times 10^{6}$ $\mathrm{CD}^{+}$cells $/ \mathrm{kg}, 0.03(0.02-0.06) \times 10^{6} \mathrm{CD}^{+}$cells $/ \mathrm{kg}, 0.04$ $(0.01-0.06) \times 10^{6} \mathrm{CD}^{+}$cells $/ \mathrm{kg}$, and $0.06(0.04-0.09) \times 10^{6}$ $\mathrm{CD} 56^{+}$cells $/ \mathrm{kg}$, respectively. The $\mathrm{CD} 34^{+}$cell dose was similar in the three groups, whereas the T-cell content obviously differed significantly.

\section{Clinical Data}

The 180-day incidence of grade II to IV acute GvHD was $50 \%$ in the unmanipulated group, $12 \%$ in the CD8-depleted group $(P=0.02)$, and $17 \%$ in the CD34-selected group $(P=0.15, \mathrm{NS})$ (Table 1$)$. The 180-day cumulative incidence of 
bacterial or fungal infection as well as the incidence of CMV reactivation did not differ significantly among the three groups (Fig. 1). The 180-day cumulative incidences of bacterial and fungal infections were $46 \%$ and $28 \%$ in the unmanipulated group, 64\% (NS) and $0 \%$ (NS) in the CD8-depleted group, and $50 \%(\mathrm{NS})$ and $20 \%(\mathrm{NS})$ in the CD34-selected group, respectively. For CMV-positive donor or recipient
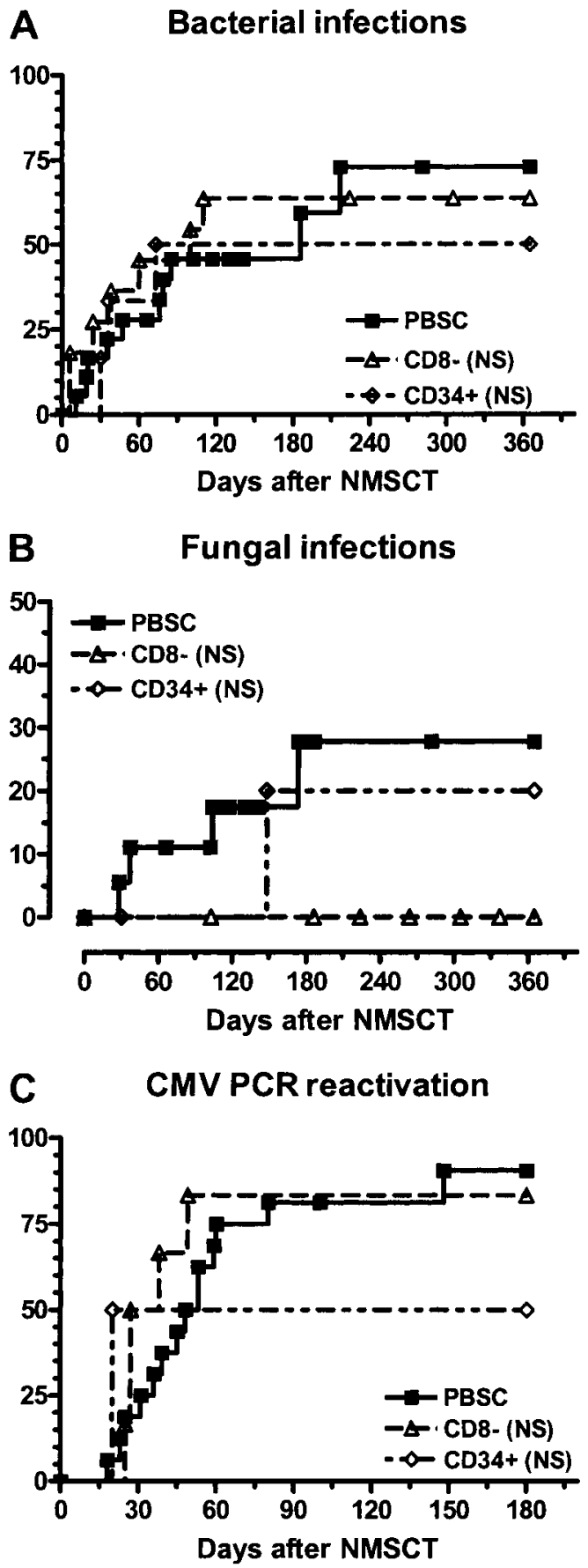

Figure 1. Cumulative incidence of (A) bacterial infections, (B) fungal infections, and (C) cytomegalovirus (CMV) polymerase chain reaction $(P C R)$ reactivation in the unmanipulated (peripheral blood stem-cell [PBSC]), CD8-depleted (CD8-), and CD34-selected (CD34+) groups. NMSCT, nonmyeloablative stem-cell transplantation. pairs, the 180-day cumulative incidence of CMV reactivation by PCR was $90 \%$ in the unmanipulated group, $83 \%$ in the CD8-depleted group, and 50\% in the CD34-selected group (NS).

\section{Recipient and Donor T Cells}

The evolution of T-cell chimerism did not significantly differ between recipients of unmanipulated versus CD8-depleted PBSC (Fig. 2A). However, CD34 selection of PBSC significantly decreased $\mathrm{CD}^{+}$-cell chimerism $(P<0.0001)$ (Fig. 2A). Median T-cell chimerisms in unmanipulated, CD8depleted, and CD34-selected recipients were 75\% (13-98), $86 \%(16-100)$, and $23 \%(19-30)$ on day $28,87 \%(37-100)$, $98 \%(28-100)$, and $32 \%(10-35)$ on day 100 , and $90 \%(33-$ $100), 92 \%$ (1-100), and $78 \%(49-95)$ on day 180 , respectively (Fig. 2A). Donor T-cell counts were similar in unmanipulated compared with CD8-depleted PBSC recipients but were significantly lower in CD34-selected PBSC recipients $(P=0.0012)$ (Fig. 2B). The T-cell count of recipient origin remained stable over time in the unmanipulated and CD8depleted groups. However, CD34-selected PBSC recipients had a higher $\mathrm{CD}^{+}$cell count of host origin $(P=0.079)$ that expanded between day 28 and 100 after the transplant (Fig. 2C). This was particularly demonstrative in a CMV-positive patient who experienced CMV reactivation 20 days after a CD34-selected NMSCT from a CMV-negative donor (Fig. 2D).

\section{Lymphocyte Subset Evolution}

The evolution of $\mathrm{CD}^{+}, \mathrm{CD}^{+}, \mathrm{CD} 4^{+} \mathrm{CD}^{+} 5 \mathrm{RA}^{+}$, $\mathrm{CD}^{+} \mathrm{CD} 45 \mathrm{RO}^{+}, \mathrm{CD}^{+}$, and $\mathrm{CD}^{+} 6^{+}$lymphocyte recovery in unmanipulated, CD8-depleted, and CD34-selected transplant recipients is shown in Figure 3. Counts of $\mathrm{CD}^{+}$ $(P=0.0053), \quad \mathrm{CD}^{+} \quad(P=0.0047), \quad$ and $\quad \mathrm{CD} 4^{+} \mathrm{CD} 45 \mathrm{RO}^{+}$ $(P=0.0120)$ cells increased with time, contrary with $\mathrm{CD}^{+} \mathrm{CD}^{2} 5 \mathrm{RA}^{+}$cells $(P=0.23$, NS) that remained stable. CD8 depletion of PBSC significantly decreased number of $\mathrm{CD}^{+}$lymphocytes $(P<0.047)$ but not that of $\mathrm{CD}^{+}, \mathrm{CD}^{+}$, $\mathrm{CD}^{+}{ }^{+} \mathrm{CD} 45 \mathrm{RA}^{+}, \mathrm{CD}^{+}{ }^{+} \mathrm{CD} 45 \mathrm{RO}^{+}, \mathrm{CD}^{+}{ }^{+}$, and $\mathrm{CD} 19^{+} \mathrm{B}$ cells between day 28 and day 180 after NMSCT. CD34 selection significantly decreased numbers of $\mathrm{CD}^{+}$cells $(P<0.001)$ as well as $\mathrm{CD}^{+} \quad(P<0.016), \mathrm{CD}^{+} \quad(P<0.001)$, $\mathrm{CD}^{+}{ }^{+} \mathrm{CD} 45 \mathrm{RA}^{+}(P<0.001)$, and $\mathrm{CD} 4{ }^{+} \mathrm{CD}^{+} 5 \mathrm{RO}^{+}(P=0.013)$ lymphocytes but not that of $\mathrm{CD}^{2} 6^{+}$cells or $\mathrm{CD} 19^{+}$lymphocytes. Moreover, contrary with CD34 selection of the graft $(P=0.002)$, neither the type of nonmyeloablative conditioning regimen nor the experience of a prior autologous transplant significantly influenced the number of $\mathrm{CD} 4^{+} \mathrm{CD} 45 \mathrm{RA}^{+}$cells on day 100 after NMSCT (Fig. 4). The same was true when the analysis was restricted to the 18 patients receiving unmanipulated PBSC. We also examined whether patient age, donor type, occurrence of $\mathrm{GvHD}$, or CMV reactivation affected $\mathrm{CD}^{+}$and $\mathrm{CD}^{+}$cell counts (Fig. 5). Age did not significantly impact on $\mathrm{CD}^{+}$and $\mathrm{CD}^{+}$counts. On the other hand, patients who received transplants from an unrelated donor had slightly lower $\mathrm{CD}^{+}$counts $(P=0.023)$, probably because they did not receive preemptive DLI. In addition, both grade II to IV acute GvHD and CMV reactivation increased the $\mathrm{CD}^{+}$count $(P=0.029$ and $P<0.001$, respectively) but did not affect the $\mathrm{CD}^{+}$count (Fig. 5). The higher $\mathrm{CD} 8^{+}$ counts in patients with GvHD was probably caused by the 
A T cell chimerism

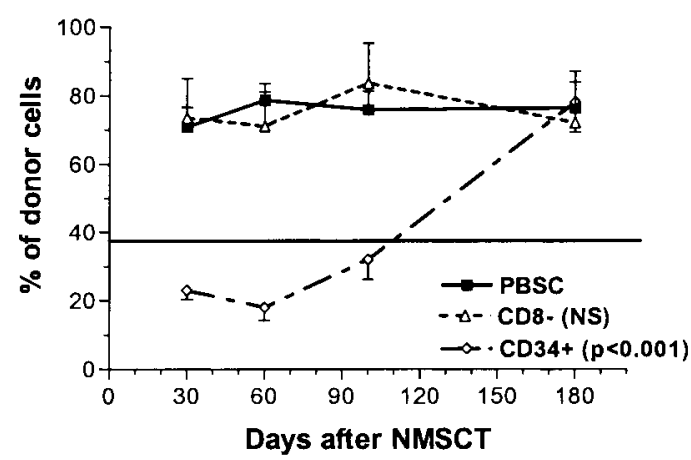

C

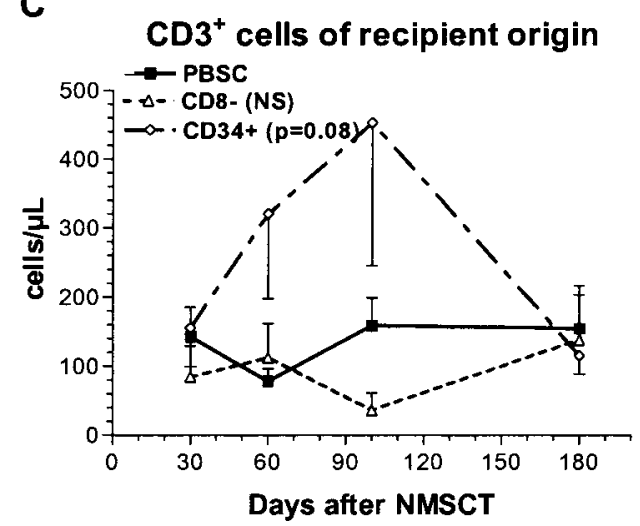

B $\mathrm{CD}^{+}$cells of donor origin

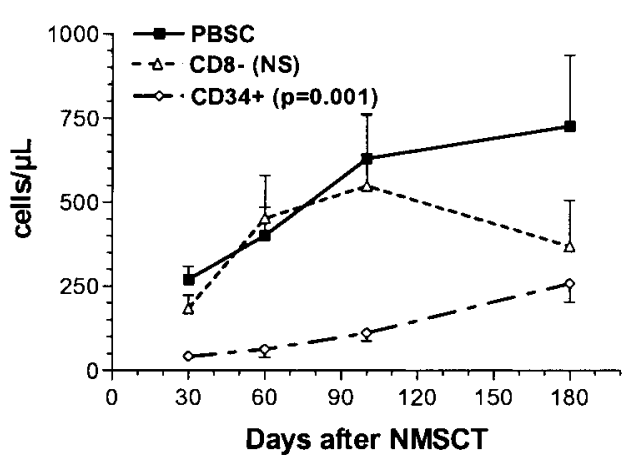

D $\mathrm{CD3}^{+}$cells of host origin in an individual patient

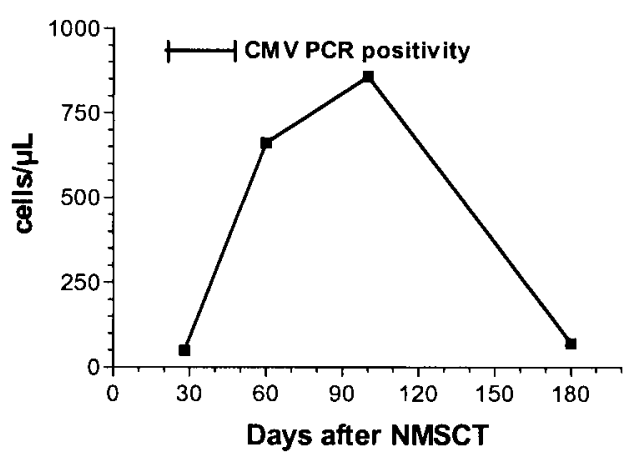

Figure 2. (A) Evolution of T-cell chimerism in the unmanipulated (PBSC), CD8-depleted (CD8-), and CD34-selected (CD34+) groups. (B) Recovery of the $\mathrm{CD3}^{+}$lymphocytes of donor origin in the unmanipulated (PBSC), CD8-depleted (CD8-), and CD34-selected (CD34+) groups. (C) Recovery of the CD3 ${ }^{+}$lymphocytes of host origin in the unmanipulated and CD8-depleted combined groups (PBSC and CD8-) and CD34-selected (CD34+) groups. (D) Recovery of host CD3 $^{+}$lymphocytes in a CMV-positive patient receiving transplant of CD34-selected PBSC from a CMV-negative donor.

higher proportion of unmanipulated PBSC recipients in this group, whereas the higher $\mathrm{CD}^{+}$counts in patients with CMV reactivation may by caused by CMV-specific CD 8 T-cell expansion. The 180-day probability of achieving normal $\mathrm{CD}^{+}, \mathrm{CD}^{+}$, and $\mathrm{CD} 4{ }^{+} \mathrm{CD} 45 \mathrm{RA}^{+}$cell counts were $52 \%$, $52 \%$, and $50 \%$ in the unmanipulated PBSC group, $58 \%$ (NS), $64 \%(\mathrm{NS})$, and $55 \%(\mathrm{NS})$ in the CD8-depleted PBSC group, and $17 \%(\mathrm{NS}), 0 \%(P=0.059)$, and $0 \%(P=0.043)$ in the CD34selected PBSC group.

\section{Cytotoxic Activity Against K562}

The cytotoxic activity of patients' PBMC against K562 was significantly higher in the CD8-depleted $(P=0.0142)$ and the CD34-selected $(P<0.001)$ groups compared with the unmanipulated group. However, this probably reflects the higher number of NK cells relative to the number of other lymphocytes in the tested PBMC from these patients. Indeed, when the cytotoxic activity was corrected by the percentage of $\mathrm{CD} 6^{+}$cells in the culture, there was no more significant differences of cytotoxic activity between the three groups (Fig. 3G).

\section{CD3 Spectratyping (Vß Score)}

Figure $3 \mathrm{H}$ shows the comparison of complexity scores for normal donors as well as 15 unmanipulated PBSC recipients, 9 CD8-depleted PBSC recipients, and 4 CD34-selected PBSC recipients for whom adequate samples of day 100 PBMC were available. The mean $\mathrm{V} \beta$ score was $188 \pm 5$ for normal donors versus $157 \pm 18$ for unmanipulated PBSC recipients $(P<0.001), 149 \pm 15$ for CD8-depleted PBSC recipients $(P<0.001)$, and $115 \pm 30$ for CD34-selected PBSC recipients $(P=0.018)$. The $\mathrm{V} \beta$ score in patients receiving transplants of CD34selected PBSC was significantly lower than in the other two groups $(P=0.002$ and 0.019$)$ for comparisons with the PBSC and CD8-depleted groups, respectively.

\section{DISCUSSION}

Previous studies have shown that T-cell reconstitution after myeloablative allogeneic transplantation is derived primarily from expansion of mature $\mathrm{T}$ cells present in the stemcell graft and that CD45RO T cells predominate early after the transplant $(22,23)$. Moreover, the T-cell repertoire was shown to be markedly abnormal within the first months after the transplant in all patients (24) but more particularly so in recipients of T-cell depleted grafts $(22,24)$. However, little is known about T-cell reconstitution after NMSCT. We performed the present study to better define immune reconstitution after NMSCT and to assess the impact of graft manipulation (CD8 depletion or CD34 selection) on early T-cell recovery.

Our study first evidenced that a significant number of $\mathrm{T}$ cells of recipient origin persist at least 180 days after the 
A

$\mathrm{CD}^{+}$

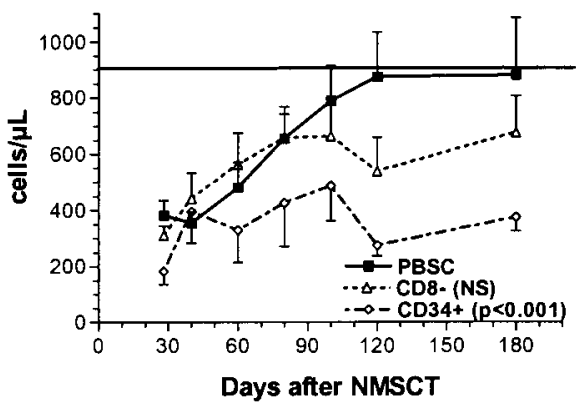

C CD4 $^{+}$CD45RA ${ }^{\text {high }}$

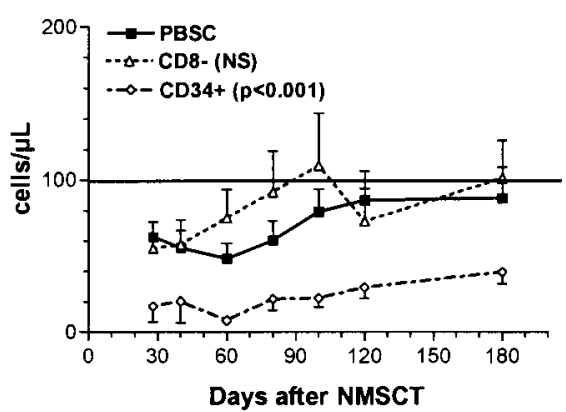

E

$$
\mathrm{CDB}^{+}
$$

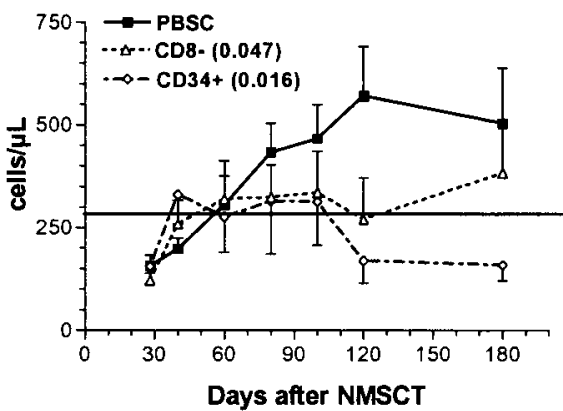

G

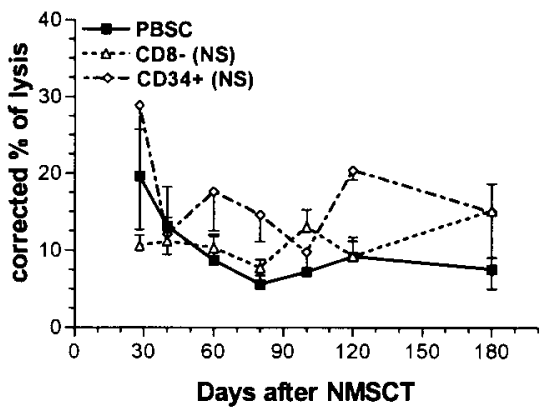

B CD4 $^{+}$

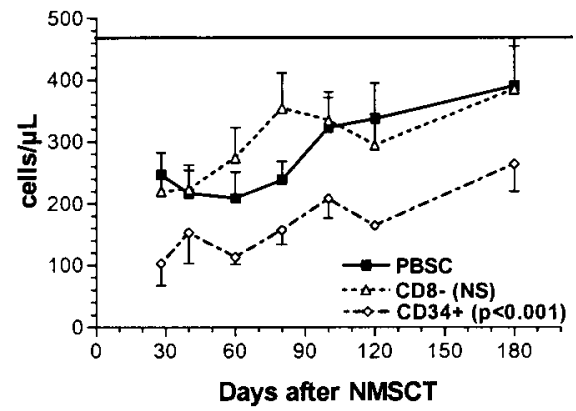

D $\mathrm{CD}^{+}{ }^{+}$D 45RO ${ }^{+}$

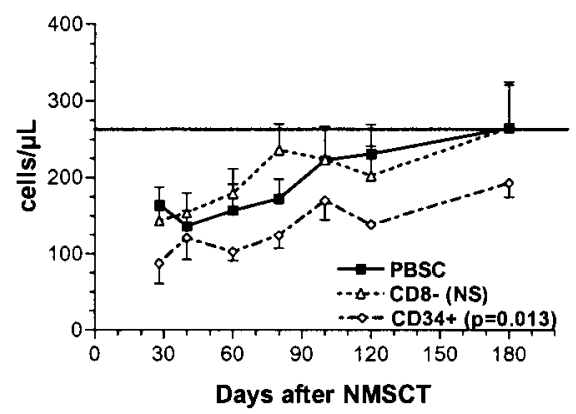

F $\mathrm{CD}^{+} 6^{+}$
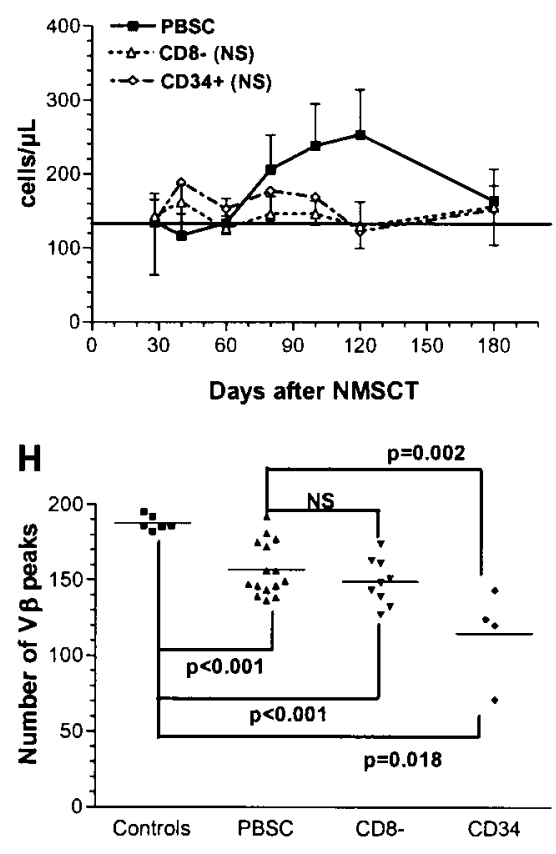

FIGURE 3. (A-G) Recovery of the various lymphocyte subsets and of cytotoxic activity against K562 (natural-killer [NK] activity) after NMSCT in the unmanipulated (PBSC), CD8-depleted (CD8-), and CD34-selected (CD34+) groups. (horizontal line) value of the third percentile in 30 normal blood donors. (H) V $\beta$ complexity score in normal controls versus unmanipulated (PBSC), CD8-depleted (CD8-) or CD34-selected (CD34+) PBSC recipients. transplant. Moreover, we showed than these recipient T cells are able to expand, at least in some recipients of a CD34selected graft. This may represent less active graft-versushost reactivity in the absence of transplanted donor T cells. Furthermore, this observation was particularly marked in a CMV-positive patient who experienced CMV reactivation 20 days after a CD34-selected NMSCT from a CMV-negative donor. It has been recently suggested that defense against CMV infections among NMSCT recipients consisted of con- tributions from both residual host memory immune responses and emerging donor graft-derived immunity (25). The large increase of $\mathrm{CD}^{+}$cells of host origin observed in our patient shortly after CMV reactivation probably illustrates the generation of a host-derived anti-CMV immune response. However, analysis of specific $\mathrm{CMV} \mathrm{CD}^{+}$and $\mathrm{CD}^{+}$cell reconstitution in the NMSCT setting is needed to confirm this hypothesis (26). The persistence of recipientderived $\mathrm{T}$ cells and the demonstration that some of them can 

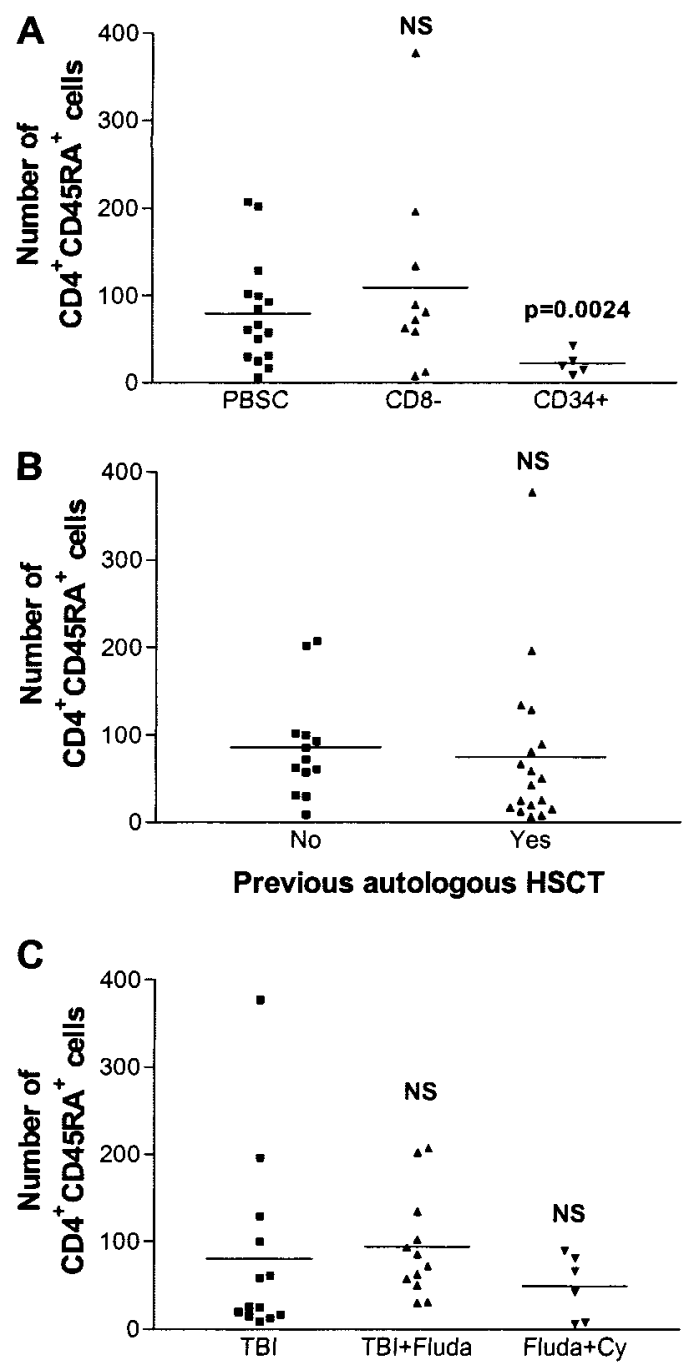

Figure 4. Comparison of day 100 counts of $\mathrm{CD}^{+} \mathrm{CD}^{2} 5 \mathrm{RA}^{+}$ cells according to (A) graft manipulation, $(B)$ previous autologous HSCT, and $(C)$ conditioning regimen.

expand may explain the lower incidence of infections observed the first months after NMSCT in comparison with conventional allogeneic HSCT (25). In confirmation of this hypothesis, a recent abstract by Maris et al. (27) showed that $\mathrm{CD}^{+}$cell counts were higher for NMSCT recipients compared with myeloablative HSCT recipients on day 30 after the allogeneic transplantation.

As observed after myeloablative HSCT, our results showed that the $\mathrm{CD}^{2} 6^{+}$cell count is the first to normalize after unmanipulated NMSCT, followed by the $\mathrm{CD} 8^{+}$lymphocyte count. Busca et al. (28) compared immune reconstitution in 30 recipients of a myeloablative allogeneic HSCT with 14 NMSCT recipients conditioned with 2 Gy TBI and fludarabine. They observed that the absolute numbers of $\mathrm{CD} 4^{+}$, $\mathrm{CD}^{+}, \mathrm{CD}_{4} 5^{+} \mathrm{RO}^{+}, \mathrm{CD} 4^{+} \mathrm{CD} 45 \mathrm{RA}^{+}$, and $\mathrm{CD} 56^{+}$cells were similar in the two groups at any time after the transplant and that $\mathrm{CD}^{+}$cells remained below normal levels up to 1 year after the transplant in both groups. Similarly Maris et al. (27) compared immune recovery in 68 recipients of a myeloablative allogeneic HSCT with 51 NMSCT recipients conditioned with 2 Gy TBI with or without fludarabine. They evidenced that absolute $\mathrm{CD}^{+}$cell counts were higher for NMSCT compared with myeloablative transplants at day 30 but lower at day 365 . Our results confirm that $\mathrm{CD} 4^{+}$and particularly naive $\mathrm{CD}^{+}\left(\mathrm{CD} 4^{+} \mathrm{CD} 45 \mathrm{RA}^{+}\right)$cell counts remained below normal for at least 6 months after the transplant. In addition, whereas $\mathrm{CD} 4^{+}$cells increased over time, this progression was clearly caused by the expansion of memory $\left(\mathrm{CD} 4^{+} \mathrm{CD} 45 \mathrm{RO}^{+}\right.$cells $)$and not to thymic generation of new $\mathrm{T}$ cells because the count of $\mathrm{CD} 4^{+} \mathrm{CD} 45 \mathrm{RA}^{+}$cells did not increase over time. Moreover, although two preliminary reports have suggested that, compared with a standard myeloablative regimen, a nonmyeloablative conditioning regimen allowed for more rapid T-cell repertoire reconstitution after allogeneic transplantation $(29,30)$, our results demonstrate that the $\mathrm{T}$-cell repertoire $(\mathrm{V} \beta$ complexity score) on day 100 remained severely restricted in NMSCT recipients. These defects may explain why the risk of late fungal and viral infections is similar in NMSCT and conventional myeloablative transplant recipients (25).

This study also demonstrates that graft manipulation directly affects T-cell reconstitution. The recovery of NK and B cells was not significantly influenced by graft manipulation. CD8 depletion of PBSC reduced both $\mathrm{CD}^{+}$and $\mathrm{CD} 8^{+}$lymphocyte counts, whereas CD34-selected PBSC recipients had very low counts of $\mathrm{CD}^{+}, \mathrm{CD} 4^{+}, \mathrm{CD} 4^{+} \mathrm{CD} 45 \mathrm{RA}^{+}$, $\mathrm{CD}^{+}{ }^{+} \mathrm{CD} 45 \mathrm{RO}^{+}$, and $\mathrm{CD} 8^{+}$lymphocytes. In particular, the speed of recovery of $\mathrm{CD} 4^{+}$and $\mathrm{CD} 4^{+} \mathrm{CD} 45^{+}$cells was similar in the three groups, but after CD34 selection, patients started with a much lower cell count at day 30 , which explains the relative delay for full reconstitution. These observations suggest that, as observed in the myeloablative transplant setting, early T-cell recovery after NMSCT depends primarily on peripheral expansion of mature $\mathrm{T}$ cells given with the graft. In addition, whereas CD8-depletion of PBSC did not decrease the number of $\mathrm{CD}^{+}$cells of donor origin, CD34-selected PBSC recipients exhibited a drastically lower number of such cells on day 100 . This observation suggests that the occurrence of a GvL effect could be seriously delayed in patients receiving transplants of CD34-selected PBSC (8). Surprisingly, we failed to demonstrate a higher incidence of infection in the CD34-selected group. However, this is probably because of the relatively small number of patients $(n=6)$ included in this group. Finally, we show that the $\mathrm{V} \beta$ complexity score was significantly lower in CD34-selected PBSC recipients compared with unmanipulated PBSC recipients. Because expansion of a few clones, particularly among CD8 ${ }^{+}$ cells, may hide the complexity in the same family, TCR complexity might be even overestimated after CD34 selection and even more so after CD8 depletion. On the other hand, it has been recently shown that, after myeloablative HSCT, the $\mathrm{V} \beta$ complexity score was associated with the chimeric status (22). We failed to find such an association in our patients.

In conclusion, our results show that, despite the persistence of a significant number of $\mathrm{T}$ cells of recipient origin, T-cell counts and particularly $\mathrm{CD} 4^{+}$and $\mathrm{CD} 4^{+} \mathrm{CD} 45 \mathrm{RA}^{+}$cell counts were low the first 6 months after NMSCT. Moreover, contrary with CD8 depletion of PBSC that only affects CD8 ${ }^{+}$ lymphocyte counts, CD34 selection of PBSC dramatically decreased both CD8 and CD4 counts. Because these observations may have important clinical applications in terms of susceptibility to infections and occurrence of the GvL effect, they need to be confirmed in a larger group of patients over 
A

$\mathrm{CD4}^{+}$

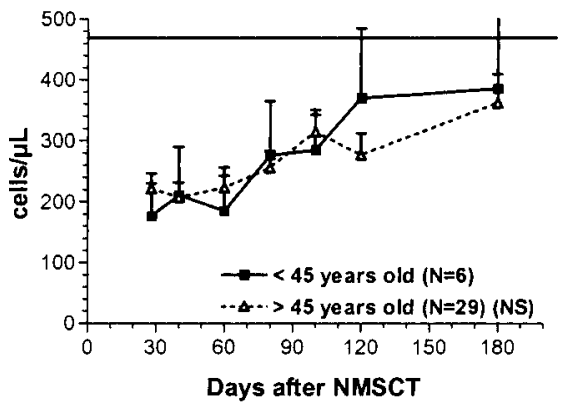

C

$\mathrm{CD}^{+}$

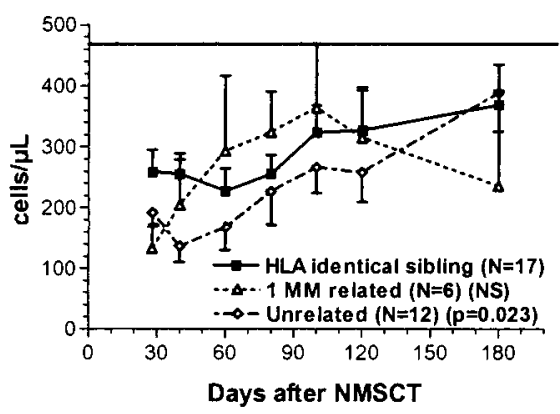

E

$\mathrm{CD4}^{+}$

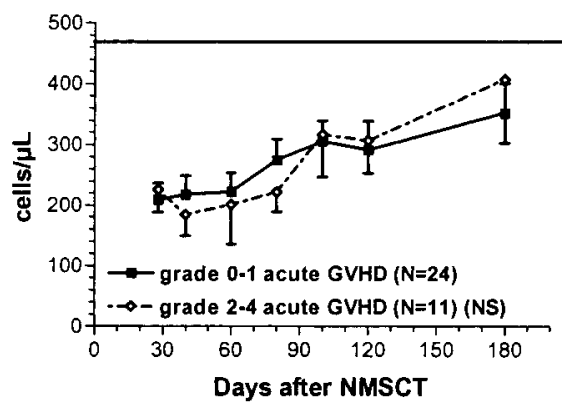

G

$\mathrm{CD}^{+}$

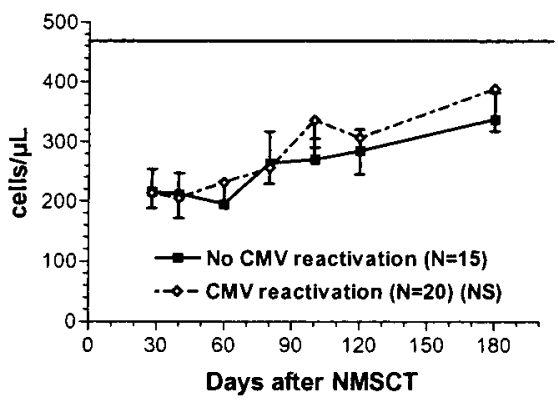

B

$\mathrm{CDB}^{+}$
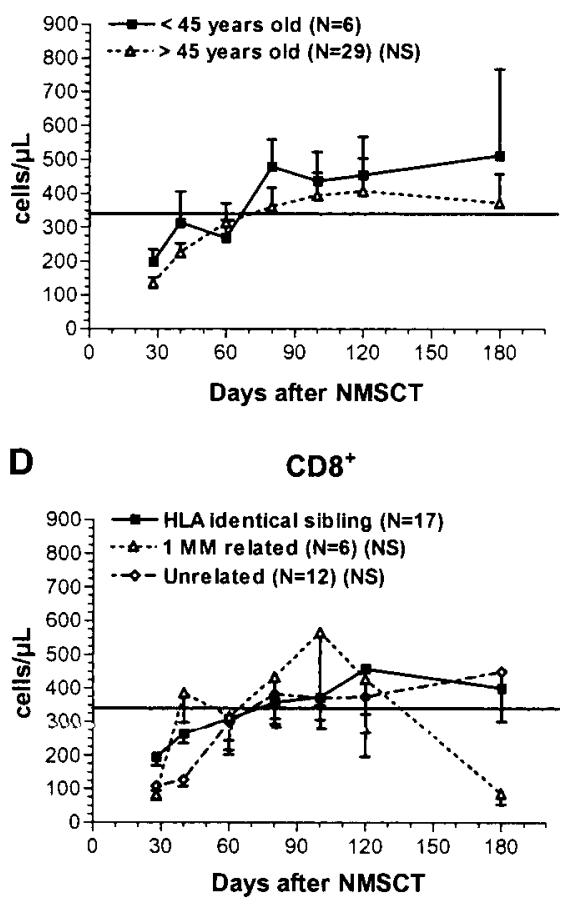

$\mathbf{F}$

$\mathrm{CDB}^{+}$

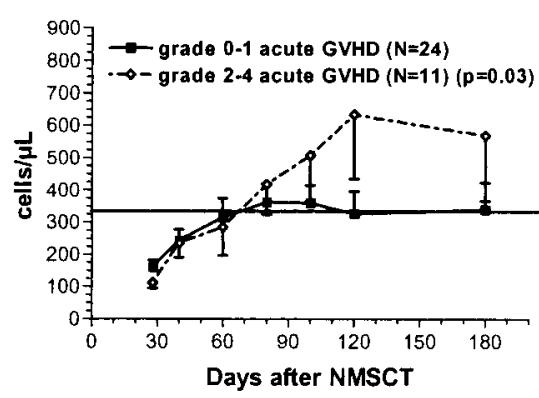

H

CD8 ${ }^{+}$

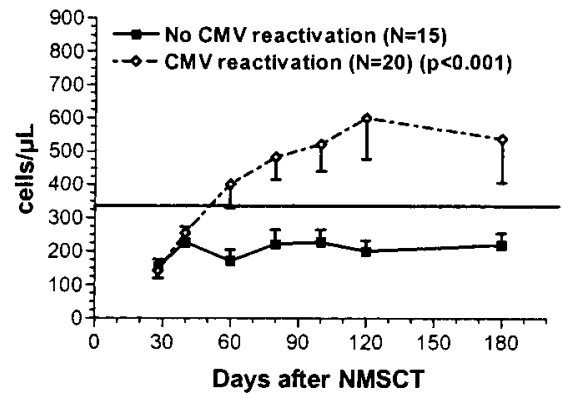

Figure 5. Impact of patient age ( $A$ and $B)$, donor type (C and $D$ ), grade II to IV graft-versus-host disease (GvHD) (E and F) and CMV reactivation ( $G$ and $H)$ on CD4+ and CD8+ counts. (horizontal line) value of the third percentile in 30 normal blood donors. longer follow-up even if the differences are already well apparent in our more modest series.

\section{REFERENCES}

1. Storb R. Allogeneic hematopoietic stem cell transplantation: yesterday, today, and tomorrow. Exp Hematol 2003; 31: 1.

2. Kolb HJ, Schattenberg A, Goldman JM, et al. Graft-versus-leukemia effect of donor lymphocyte transfusions in marrow grafted patients. European Group for Blood and Marrow Transplantation Working Party Chronic Leukemia. Blood 1995; 86: 2041.
3. Baron F, Beguin Y. Adoptive immunotherapy with donor lymphocyte infusions after allogeneic HPC transplantation. Transfusion 2000; 40: 468.

4. Baron F, Beguin Y. Nonmyeloablative allogeneic hematopoietic stem cell transplantation. J Hematother Stem Cell Res 2002; 11: 243.

5. McSweeney PA, Storb R. Mixed chimerism: preclinical studies and clinical applications. Biol Blood Marrow Transplant 1999; 5: 192.

6. McSweeney PA, Niederwieser D, Shizuru J, et al. Hematopoietic cell transplantation in older patients with hematologic malignancies: replacing high-dose cytotoxic therapy with graft-versus-tumor effects. Blood 2001; 97: 3390 
7. Niederwieser D, Maris M, Shizuru JA, et al. Low-dose total body irradiation (TBI) and fludarabine followed by hematopoietic cell transplantation (HCT) from HLA-matched or mismatched unrelated donors and postgrafting immunosuppression with cyclosporine and mycophenolate mofetil (MMF) can induce durable complete chimerism and sustained remissions in patients with hematological diseases. Blood 2003; 101: 1620.

8. Childs R, Clave E, Contentin N, et al. Engraftment kinetics after nonmyeloablative allogeneic peripheral blood stem cell transplantation: full donor T-cell chimerism precedes alloimmune response. Blood 1999; 94: 3234.

9. Ho VT, Soiffer RJ. The history and future of T-cell depletion as graftversus-host disease prophylaxis for allogeneic hematopoietic stem cell transplantation. Blood 2001; 98: 3192.

10. Nimer SD, Giorgi J, Gajewski JL, et al. Selective depletion of CD8+ cells for prevention of graft-versus-host disease after bone marrow transplantation. Transplantation 1994; 57: 82.

11. Giralt S, Hester J, Huh Y, et al. CD8-depleted donor lymphocyte infusion as treatment for relapsed chronic myelogenous leukemia after allogeneic bone marrow transplantation. Blood 1995; 86: 4337.

12. Alyea EP, Weller E, Schlossman R, et al. T-cell-depleted allogeneic bone marrow transplantation followed by donor lymphocyte infusion in patients with multiple myeloma: induction of graft-versus-myeloma effect. Blood 2001; 98: 934.

13. Barrett AJ, Mavroudis D, Tisdale J, et al. T cell-depleted bone marrow transplantation and delayed T cell add-back to control acute GVHD and conserve a graft-versus-leukemia effect. Bone Marrow Transplant 1998; 21: 543.

14. Baron F, Siquet J, Schaaf-Lafontaine N, et al. Pre-emptive immunotherapy with CD8-depleted donor lymphocytes after CD34-selected allogeneic peripheral blood stem cell transplantation. Haematologica 2002; 87: 78 .

15. Baron F, Beguin Y. Preemptive cellular immunotherapy after T-cell-depleted allogeneic hematopoietic stem cell transplantation. Biol Blood Marrow Transplant 2002; 8: 351.

16. Baron F, Baudoux E, Frere P, et al. nonmyeloablative stem cell transplantation with CD8-depleted or CD34-selected peripheral blood stem cells. J Hematother Stem Cell Res 2002; 11: 301.

17. Baron F, Frere P, Baudoux E, et al. Low incidence of acute graft-versushost disease after non-myeloablative stem cell transplantation with CD8-depleted peripheral blood stem cells: an update. Haematologica 2003; 88: 820 .

18. Przepiorka D, Weisdorf D, Martin P, et al. 1994 Consensus Conference on
Acute GVHD Grading. Bone Marrow Transplant 1995; 15: 825.

19. Margolis J, Vogelsang G. Chronic graft-versus-host disease. J Hematother Stem Cell Res 2000; 9: 339 .

20. Baron F, Turhan AG, Giron-Michel J, et al. Leukemic target susceptibility to natural killer cytotoxicity: relationship with BCR-ABL expression. Blood 2002; 99: 2107.

21. Genevee C, Diu A, Nierat J, et al. An experimentally validated panel of subfamily-specific oligonucleotide primers (V alpha $1-\mathrm{w} 29 / \mathrm{V}$ beta 1-w24) for the study of human $\mathrm{T}$ cell receptor variable $\mathrm{V}$ gene segment usage by polymerase chain reaction. Eur J Immunol 1992; 22: 1261.

22. Wu CJ, Chillemi A, Alyea EP, et al. Reconstitution of T-cell receptor repertoire diversity following $\mathrm{T}$-cell depleted allogeneic bone marrow transplantation is related to hematopoietic chimerism. Blood 2000; 95: 352.

23. Storek J, Dawson MA, Storer B, et al. Immune reconstitution after allogeneic marrow transplantation compared with blood stem cell transplantation. Blood 2001; 97: 3380.

24. Roux E, Helg C, Dumont-Girard F, et al. Analysis of T cell repopulation after allogeneic bone marrow transplantation: significant differences between recipients of $\mathrm{T}$ cell depleted and unmanipulated grafts. Blood 1996; 87: 3984.

25. Junghanss C, Boeckh M, Carter RA, et al. Incidence and outcome of cytomegalovirus infections following nonmyeloablative compared with myeloablative allogeneic stem cell transplantation, a matched control study. Blood 2002; 99: 1978.

26. Foster AE, Gottlieb DJ, Sartor M, et al. Cytomegalovirus-specific CD4+ and CD8+ T-cells follow a similar reconstitution pattern after allogeneic stem cell transplantation. Biol Blood Marrow Transplant 2002; 8: 501.

27. Maris MB, Boeckh M, Dawson MA, et al. Immunologic recovery after nonmyeloablative compared to conventional hematopoietic stem cell transplantation (HSCT) using peripheral blood stem cells (PBSC) from HLA identical sibling donors. Blood 2002; 100: 3329.

28. Busca A, Falda M, Genetta C, et al. Immune reconstitution following allogeneic nonmyeloablative stem cell transplantation (NST). Bone Marrow Transplant 2002; 29(Suppl 2): s155.

29. Friedman TM, Varadi G, Hopely DD, et al. Nonmyeloablative conditioning allows for more rapid T-cell repertoire reconstitution following allogeneic matched unrelated bone marrow transplantation compared to myeloablative approaches. Biol Blood Marrow Transplant 2001; 7: 656.

30. Chao NJ, Liu CX, Rooney B, et al. Nonmyeloablative regimen preserves "niches" allowing for peripheral expansion of donor T-cells. Biol Blood Marrow Transplant 2002; 8: 249. 